\title{
Application of the precautionary principle to taxa of uncertain status: the case of the Bellinger River turtle
}

\author{
Arthur Georges ${ }^{1, *}$, Ricky-John Spencer ${ }^{1,2}$, Michael Welsh ${ }^{3}$, H. Bradley Shaffer ${ }^{4}$, \\ Rachael Walsh ${ }^{1}$, Xiuwen Zhang ${ }^{1}$ \\ ${ }^{1}$ Institute for Applied Ecology, University of Canberra, ACT 2601, Australia \\ ${ }^{2}$ Native and Pest Animal Unit, School of Natural Sciences, University of Western Sydney, Locked Bag 1797, Penrith South, \\ New South Wales 2750, Australia \\ ${ }^{3}$ Michael Welsh Fauna Consultant, 7 Chisholm Road, Gerringong, New South Wales 2534, Australia \\ ${ }^{4}$ Department of Evolution and Ecology, University of California, One Shields Ave, Davis, California 95616, USA
}

\begin{abstract}
Legislative and regulatory frameworks for conserving biodiversity often focus on the species as a fundamental unit for protection. In cases where the taxonomic or conservation status of a species is uncertain, the precautionary principle may be invoked in listing suspected but as yet undescribed taxa as vulnerable or endangered. In this paper, we present an evaluation of the taxonomic status of what has been regarded as a distinctive but as yet undescribed species of freshwater turtle, declared endangered in the Action Plan for Australian Reptiles and vulnerable in the schedules of state and federal conservation acts. Using mitochondrial sequence variation, we show that the Bellinger River turtle is an unremarkable population of a common and widespread species, Emydura macquarii. In addition, we present evidence suggesting that it may have been recently introduced to, or may be a recent invader of, the Bellinger River (New South Wales, Australia) where it may come to compete with Myuchelys georgesi, an endemic found only in the Bellinger River. Our study illustrates the need to couple fundamental research with on-ground action early in an adaptive management context, particularly where taxonomic status of the target species is uncertain. Short-term cost savings of failing to do so may come to be greatly exceeded by longer-term opportunity loss where conservation dollars are limited.
\end{abstract}

KEY WORDS: Taxonomic impediment - Emydura macquarii - Myuchelys georgesi - Elseya · Mitochondrial sequence variation

\section{INTRODUCTION}

Biodiversity loss is one of the greatest challenges of the 21st century (McGlothlin 2004). Changes brought about by growth of human populations and per capita consumption are driving many changes, with adverse consequences for wildlife on all continents, through the combined influences of over-exploitation (Lauck et al. 1998, Rosenberg 2003), deforestation, habitat degradation, fragmentation or loss (Fahrig 1997, Yamaura et al. 2011), exotic predators and diseases (Berger et al. 1998, Daszak et al. 1999, Lips et al. 2006) and climate change (Walther et al. 2002).
Biodiversity encapsulates diversity of biotic communities, diversity of species in those communities, genetic diversity within species, and the ecological and evolutionary processes that create and maintain that diversity (Wilson \& Peter 1988, World Resources Institute 1992, de Long 1996). However, in many legislative and regulatory systems, the species remains the primary focus for conservation (Hey et al. 2003). As new species are discovered, rapid assessment of their status becomes a priority so that measures can be taken to ensure that they are protected (Pauly et al. 2007). In some jurisdictions, such as Australia, the precautionary principle (Raffensperger et al. 1999) is used to allow 
protection and remediation to be initiated in advance of formal description of 'species' thought to be at risk. The Australian Environmental Protection and Biodiversity Conservation (EPBC) Act and most state jurisdictions allow nomination of populations regarded as, or suspected to be, distinct species or subspecies, some of which await formal description. This practice leads to satisfactory conservation outcomes when the need for management intervention is pressing, but the information needed to make sound taxonomic judgements has yet to be fully realised. The risk is that conservation resources may be allocated on taxa that later turn out to be of relatively low conservation value (Zhu et al. 1998). Such would occur when the initial judgement on the validity of a taxon is not borne out by subsequent investigation.

Here we present an example where the precautionary principle was applied to what was, on the basis of anecdotal evidence, a 'species' at risk - a distinctive form of freshwater turtle found only in the Bellinger River of eastern Australia (Cann 1998). Listed as vulnerable in the Reptile Action Plan (Cogger et al. 1993) as Emydura signata, vulnerable in the Schedules of the Threatened Species Act, New South Wales (NSW NPWS 2001) as E. macquarii, Bellinger River Form, and vulnerable in the national EPBC Act (Commonwealth of Australia 1999) as E. macquarii signata (Bellinger River, NSW), this 'species' of turtle was used as a flagship to marshal community support for a range of initiatives in riparian and riverine restoration and invasive fox control (NSW NPWS 2001). Discovered in 1990 in a single waterhole in the middle reaches of the Bellinger River by P. King (King \& Heatwole 1994) as part of broader studies and again at the same location in 1992 by Cann (1998), captures of the Bellinger Emydura were initially extremely rare. Recent surveys funded by the NSW Government have shown progressive increases in abundance and distribution in the Bellinger River, to the point where the turtles are now widespread and common in the drainage. However, the question of whether the Bellinger River Emydura is a distinctive taxon or an unremarkable representative of the more widespread E. macquarii macquarii (sensu Georges \& Thomson 2010) remains unanswered. So too does the more difficult question of whether it is a relict endemic having barely endured and recovered from a catastrophic decline, or whether it is a recent introduction to the river, possibly with human assistance, that has established and is in the early stages of invasion. Both questions are critical to deciding what management intervention is required, if any, and the value of the Bellinger River Emydura as a flagship species of conservation concern.

In this paper, we report the results of the most recent survey into the distribution and abundance of the
Bellinger River Emydura and use mitochondrial DNA sequences of Emydura spp. and the endemic Bellinger River sawshell turtle Myuchelys georgesi to address these 2 questions. Taxonomic research is in decline despite the biodiversity imperative (Hopkins \& Freckleton 2002), and in Australia is compounded by the proliferation of names attached to taxonomic concepts with little or no support (see Georges \& Thomson 2010, Oliver \& Lee 2010) and uncritically adopted by state and federal agencies. The role of a well-founded taxonomy in underpinning conservation is well established (Mace 2004). Our study serves to highlight the importance of a commitment to fundamental taxonomic research, concurrent with the early stages of precautionary management intervention, to address the uncertainty in knowledge that leads to the invocation of the precautionary principle in the listing of new taxa whose taxonomic status is uncertain.

\section{MATERIALS AND METHODS}

Turtles were collected between 1 and 17 April 2007 in the Bellinger and Kalang Rivers (New South Wales, Australia) (Fig. 1) by hand with mask and fins, in cathedral traps (Legler 1960, as modified by Georges et al. 2006) baited with liver and sardines, and with dipnets by spotlight at night. Traps were checked at intervals of 4 to $10 \mathrm{~h}$, re-baited after approximately $24 \mathrm{~h}$, and left in place for 24 to $48 \mathrm{~h}$ at each location.

Mature males were distinguished from mature females based on tail length (Georges et al. 2006), and the minimum size of visually identifiable males $(118 \mathrm{~mm}$ carapace length) was used as the upper size limit for all juveniles. A small sliver of tissue was taken from the outside edge of the vestigial toe of the rear foot, stored in $75 \%$ ethanol for DNA analysis, and later transferred to $-20^{\circ} \mathrm{C}$ storage freezers. Each turtle was photographed (dorsal and ventral view, lateral view of the head) and presence or absence of the cervical scute and/or head shield was noted, characters which typically differ between Emydura macquarii and Myuchelys georgesi. All turtles were released within $2 \mathrm{~h}$ at their point of capture.

DNA was extracted from the 76 specimens of Emydura macquarii, 16 Myuchelys georgesi, 3 suspected hybrids and 1 suspected specimen of M. latisternum from the Bellinger River drainage (including the Kalang tributary). An additional 34 specimens of $E$. macquarii from 3 localities in the vicinity of Coffs Harbour were also extracted as a second phase in the study. Genomic DNA was extracted from skin tissues using salt extraction or Chelex (Bio-Rad) beads as described by FitzSimmons et al. (1997). Sub-samples of skin were digested overnight at $55^{\circ} \mathrm{C}$ in $300 \mu$ lof buffer (40 mM Tris, 20 mmol EDTA, $100 \mathrm{mmol} \mathrm{NaCl}$ ), $20 \mu \mathrm{l}$ of 


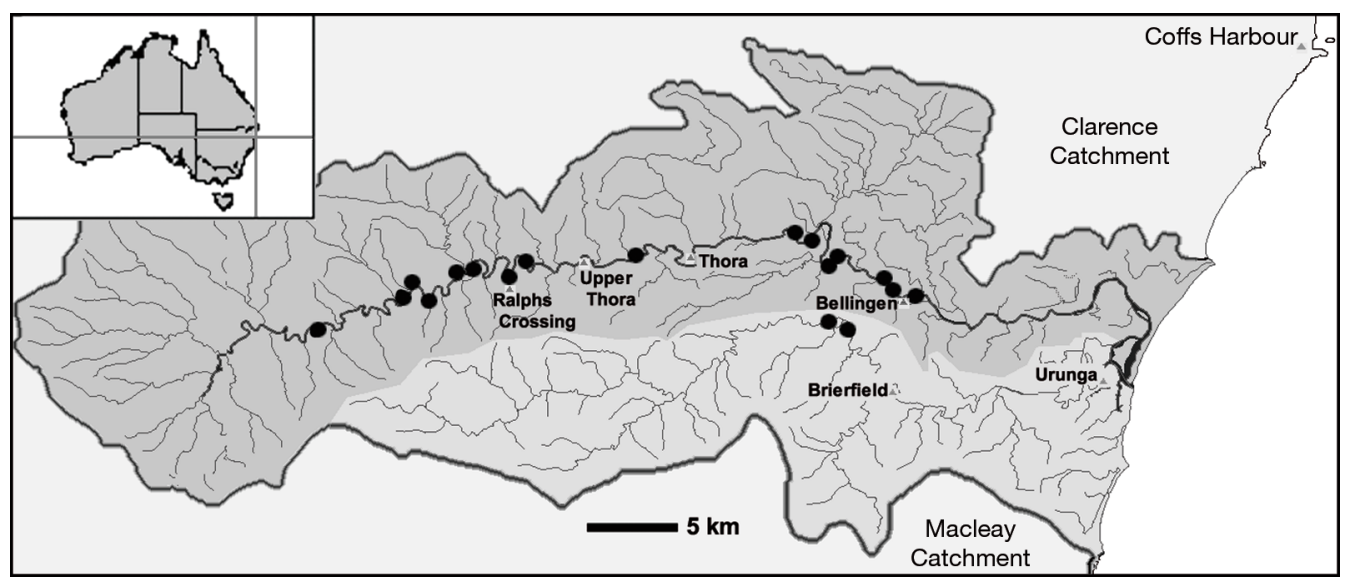

Fig. 1. Bellinger catchment (at the junction of the crosshairs in the inset) showing the capture localities of the Bellinger Emydura $(\bullet)$. The Kalang River is essentially a tributary of the Bellinger River, and is shown on the map as running through Urunga and Brierfield (lighter shading)

$10 \%$ sodium dodecyl sulphate (SDS) and $10 \mu \mathrm{l}$ of $10 \mathrm{mg}$ $\mathrm{ml}^{-1}$ Proteinase K. DNA was salt extracted and precipitated with $150 \mu \mathrm{l}$ of $7.5 \mathrm{~mol}$ ammonium acetate and 1 $\mathrm{ml}$ of $100 \%$ ethanol, washed with $70 \%$ ethanol, and then re-suspended in $50 \mu \mathrm{l}$ of water. A $4 \mu \mathrm{l}$ subsample of each extraction was run out on a gel to confirm the success of the extraction. PCR used the control region (CR) primers TCR500 and EMYTHR (Engstrom et al. 2004). PCR products (50 $\mu \mathrm{l}$ of each sample) were precipitated with $50 \mathrm{\mu l}$ of $20 \%$ polyethylene glycol (PEG), washed with $80 \%$ ethanol and re-suspended in $13 \mu \mathrm{l}$ of water. The cleanup PCR products were packaged and sent to Macrogen (Seoul) for sequencing. The resulting sequences were checked, analysed and aligned using Geneious Pro 4.6.4. Additional CR sequences for a range of populations of the southern Emydura were sequenced at the UC Davis DNA sequencing facility by H. B. S. using standard protocols (e.g. Spinks et al. 2010).

Unique mitochondrial haplotypes were identified using FaBox (Villesen 2007). A phylogeny for those haplotypes was constructed under the maximum parsimony criterion and standard default settings using the computer package PAUP* (Swofford 1996) and 2 Northern Territory Emydura victoriae haplotypes as outgroups. The full analysis will be presented elsewhere (H. B. Shaffer et al. unpublished). A haplotype network was constructed for the Bellinger River haplotypes using the programme TCS (Clement et al. 2000).

\section{RESULTS}

Analysis of the $428 \mathrm{bp}$ CR haplotypes of the 76 specimens of Emydura macquarii from the Bellinger River yielded 6 unique haplotypes differing by between 1 and $4 \mathrm{bp}$ (Table 1). In contrast, the endemic Myuchelys georgesi yielded only a single haplotype (Genbank accession nos. JN088723-30). The sequences generated by the UC Davis DNA sequencing facility yielded a further 68 unique haplotypes from across the range of the southern Emydura (Table 2). One of these haplotypes was for a Bellinger Emydura collected by P. King, and its haplotype was identical to another Bellinger Emydura from the present study.

The haplotypes of the Bellinger River fell within a clade comprising the Bellinger, Clarence, Macleay, Nambucca and Hastings drainages. None of the 6 haplotypes identified in the Bellinger were found in drainages outside this small collection of adjacent drainages (Table 2)

The network diagram generated for the Bellinger Emydura haplotypes shows the most parsimonious evolutionary relationship among these haplotypes, with 4 of the 6 haplotypes common, and haplotype HP9 as the most parsimonious choice of the ancestral haplo-

Table 1. Emydura macquarii. Uncorrected distances between control region haplotypes (HP) found in turtles from the Bellinger River and adjacent drainages. The lower matrix shows raw base pair differences; the upper matrix shows percentage differences $(\mathrm{N}=428 \mathrm{bp})$. Haplotype 10 is a related haplotype from the Clarence River that was not detected in the Bellinger River

\begin{tabular}{|lccccccc|}
\hline & HP7 & HP8 & HP9 & HP10 & HP11 & HP12 & HP13 \\
\hline HP7 & & 0.24 & 0.47 & 0.71 & 0.71 & 0.94 & 0.71 \\
HP8 & 1 & & 0.24 & 0.47 & 0.47 & 0.71 & 0.48 \\
HP9 & 2 & 1 & & 0.24 & 0.24 & 0.47 & 0.24 \\
HP10 & 3 & 2 & 1 & & 0.47 & 0.71 & 0.47 \\
HP11 & 3 & 2 & 1 & 2 & & 0.24 & 0.48 \\
HP12 & 4 & 3 & 2 & 3 & 1 & & 0.72 \\
HP13 & 3 & 2 & 1 & 2 & 2 & 3 & \\
\hline
\end{tabular}


Table 2. Emydura macquarii. Haplotypes (HP) ordered by locality for $428 \mathrm{bp}$ of mitochondrial control region for the southern Emydura (cf macquarii). Bellinger River haplotypes are in bold. MDB: Murray-Darling Basin

\begin{tabular}{|llll|}
\hline Drainage & Haplotypes & Drainage & Haplotypes \\
\hline New South Wales & & & \\
Bellinger R. & HP7, HP8, HP9, HP11, HP12, HP13 & MDB Murray R. & HP43, HP44, HP45, HP46 \\
Bulloo R. & HP47, HP73 & MDB Murrumbidgee R. & HP42, HP44 \\
Clarence R. & HP9, HP10, HP13, HP52 & MDB Namoi R. & HP48 \\
Hastings R. & HP8 & Nambucca R. & HP8 \\
Hunter R. & HP1, HP2, HP3, HP4 & Paroo R. & HP51 \\
Macleay R. & HP8 & Richmond R. & HP15 \\
MDB Border R. & HP46, HP47, HP48, HP54 & Richmond R. & HP16 \\
MDB Lachlan R. & HP46 & Richmond R. & HP17 \\
MDB Macquarie R. & HP50 & Richmond R. & HP18 \\
Queensland & HP33, HP52 & Johnstone R. & HP39, HP40 \\
Brisbane R. & HP72 & Herbert R. & HP22 \\
Bulloo R. & HP26, HP27, HP28, HP29, & Johnstone R. & HP20 \\
Burdekin R. & HP30, HP31, HP37 & & HP49, HP59, HP60, HP62, \\
Burnett R. & HP55, HP58, HP59, HP61 & Mary R. & HP64, HP65, HP67, HP68 \\
Cooper Creek & HP70, HP71, HP72, HP73 & HP48 \\
Endeavour R. & HP25 & MDB Condamine-Balonne & HP41, HP47, HP74 \\
Fitzroy-Dawson R. & HP14, HP34, HP35, HP36, HP38, HP53, & PDoserpine & HP37 \\
Fraser Is. & HP56, HP57, HP63, HP66, HP69 & Ross R. & HP19, HP20, HP23, HP24 \\
Hahn R. & HP20, HP21 & Tweed R. & HP64 \\
\hline
\end{tabular}

type (Fig. 2). Of the Bellinger haplotypes, HP13 and HP9 are shared with the Clarence River, HP8 (and possibly the 1 bp variant HP7) are shared with the Macleay, Nambucca and Hastings Rivers. Haplotypes HP11 and HP12 were unique to the Bellinger drainage.

The distribution of haplotypes within the Bellinger River drainage basin is also instructive (Fig. 3). While one might expect some genetic differentiation be-

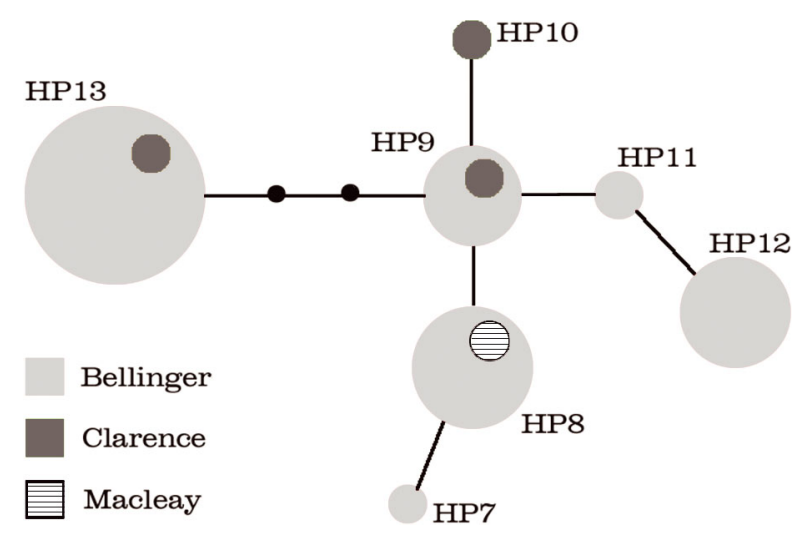

Fig. 2. Emydura macquarii. Maximum parsimony network showing the relationship among haplotypes from the Bellinger River. Area of the circles is proportional to the frequency of the haplotypes in the population ( $\mathrm{n}=72$ turtles). Small black dots represent transitionary haplotypes not represented in our sample. Network constructed using the computer programme 'TCS' (Clement et al. 2000) tween the Bellinger River proper and the Kalang River, complete riverine connectivity within the Bellinger River and independent ecological evidence of substantial turtle movements within the system (Spencer 2006) would argue against spatial genetic differentiation within the Bellinger River. Yet we are seeing such differentiation. Of particular interest are the 2 haplotypes (HP11 and HP12) that were not detected in our samples from outside the Bellinger drainage. All 15 specimens bearing these haplotypes were found in a single waterhole $750 \mathrm{~m}$ upstream from the centre of the township of Bellingen. In a small, continuously flowing,

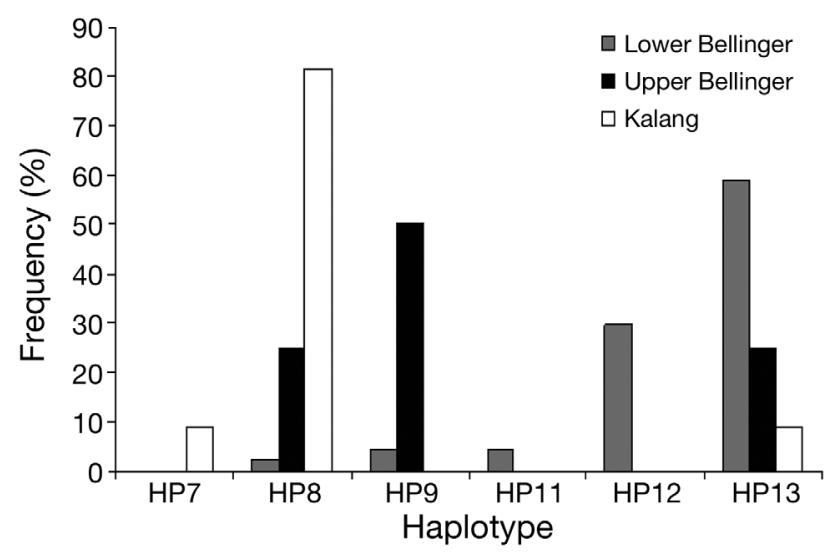

Fig. 3. Emydura macquarii. Distribution of haplotypes within the Bellinger River drainage $(n=72)$. Vertical axis shows percentage representation for each haplotype across localities 
highly connected river system, the most plausible explanation for this is a recent introduction of more than 1 specimen. In 2000, 3 of several Emydura brought to the Bellingen township from a seizure in Coffs Harbour escaped into the river (B. Nesbitt pers. comm.). It may be that these are the source of these localised haplotypes, which have not yet had time to propagate throughout the system. Subsequent screening of populations in the vicinity of the township of Coffs Harbour in search of the source of these specimens yielded 3 haplotypes (15 individuals, 3 localities, HP9, HP12 and HP13). Note that HP12 was found in the Bellinger River only at the release site near Bellingen township.

\section{DISCUSSION}

River turtles of the genus Emydura are widely distributed in Australia and southern New Guinea, wherever permanent waters are found, with the exception of the south-western corner of the mainland Australia and Tasmania (Georges \& Thomson 2010). Their species-level taxonomy has been controversial, and issues of species delineation remain unresolved in tropical northern Australia. Southeastern and eastern Australia appear to be occupied by a single widespread polytypic species (Georges \& Adams 1996) that has variously been divided into species and subspecies (Cann 1998, McCord et al. 2003). One recent classification (Georges \& Thomson 2010) has E. macquarii macquarii as occupying the Murray-Darling drainage and adjacent coastal drainages from the Brisbane River south to the Hawkesbury-Nepean River of the Sydney region. These east coastal populations are quite divergent genetically (H.B. Shaffer et al. unpublished), differ in minor morphological attributes (Cann 1998), and vary dramatically in maximum body size (Cann 1998). They have been referred to variously as E. signata (Iverson 1992), E. macquarii signata (Cogger 2000) or as a series of single-drainage subspecies (Cann 1998). The Bellinger Emydura has been regarded as one of these distinctive forms of Emydura signata or E. macquarii.

There is evidence that the Bellinger Emydura has recently increased in abundance and distribution within the Bellinger drainage. In the 15 to $20 \mathrm{yr}$ prior to the publication of the Action Plan for Australian Reptiles (Cogger et al. 1993), opportunistic widespread searching for this taxon along the length of the Bellinger River (King \& Heatwole 1994, Cann 1998, Allanson \& Georges 1999) had its distribution restricted to 1 locality, Ralph's Crossing, $11 \mathrm{~km}$ upstream of Thora. Between 2000 and 2005, the river was both opportunistically and systematically searched annually for Bellinger River Emydura (Spencer \& Thompson 2000,
Blamires et al. 2005), but this resulted in only 11 new individuals captured, all upstream of Thora and close to Ralph's Crossing. The survey we report in this paper, conducted in 2007, captured 76 individuals distributed throughout the drainage, a substantial proportion of which were less than $10 \mathrm{yr}$ old (Spencer et al. 2007). Notwithstanding variation in the methods and efficiencies of these surveys, there is little doubt that the Bellinger Emydura has moved from a situation of critically low numbers to a more secure population from the time of first discovery to the present. The critical issue is whether these population trends are of a distinctive endemic population recovering from the brink of extinction, or the consolidation and rapid population growth of a regionally abundant taxon recently introduced to the Bellinger River. From a conservation perspective, is there cause to rejoice or cause for concern?

Our genetic data do not support the proposition that the Bellinger Emydura is a distinctive species or subspecies (Cann 1998), nor do they support its listing as a threatened taxon in the Action Plan for Australian Reptiles, the Schedules of the Threatened Species Act, NSW, or the schedules of the national EPBC Act. Indeed, the Bellinger Emydura is genetically unremarkable, with very little mitochondrial genetic divergence between the Bellinger populations of E. macquarii and those of the adjacent Macleay, Hastings, Nambucca and Clarence drainages (Table 1). There is no evidence in our data to suggest that the Bellinger form should be regarded as a separate biological species, a sub-species, or indeed a distinct evolutionarily significant unit (ESU; sensu Moritz 1994). The Bellinger population shares haplotypes with adjacent systems to the north and south and so shares haplotypes with populations regarded as unremarkable representatives of the widespread southern Emydura (Georges \& Thomson 2010). The diagnostic morphological features identified by Cann (1998), such as the flaring of the carapace and the colour of the iris, are both highly variable among populations of the southern Emydura, and no rigorous morphological analysis has been published to support the diagnosis. There is no evidence to suggest that the Bellinger population of E. macquarii is anything more than a population of a widespread species occupying sub-optimal habitat (simple channel, oligotrophic, clear-water river flowing over a gravel bed, with heavily forested banks). The proposition that the Bellinger Emydura is an isolated relict endemic species or subspecies (Cogger et al. 1993, Cann 1998), now in the early stages of recovery, is without support, based on the limited genetic data presented here.

Our data are consistent with the proposition that some, if not all, of the genetic variation within the Bellinger Emydura is a result of recent introductions or invasions. 
Distinguishing between human-induced introduction or natural invasion from adjacent drainages is more problematic because any evidence is by necessity inferential and the 2 possibilities are not mutually exclusive. On the basis of the haplotype analysis, we can confidently eliminate the commercial pet trade operating legally in South Australia (JB's Turtles, Barmera) as a possible source of introductions, and indeed can confidently eliminate any of the drainages occupied by the southern Emydura outside those in the neighbouring region of the Bellinger (Clarence, Macleay, Nambucca, Hastings). It is unusual to see such diversity in mitochondrial haplotypes in a species occupying a drainage as small as the Bellinger (6 mitochondrial haplotypes, 4 of which are well represented), and in a population as small as that suspected for the Bellinger Emydura. Contrast this with the single haplotype for the much more abundant Myuchelys georgesi in the same drainage. Three of the 4 common Emydura haplotypes are shared with adjacent drainages. Given these observations, our interpretation is that the most likely scenario is that some of the Bellinger haplotypes are derived from the more substantial turtle populations in adjacent drainages, either through natural dispersal or through human-mediated movement of turtles. The reliable reports of Emydura being released into the Bellinger River from adjacent catchments (Coffs Creek region; B. Nesbitt pers. comm.), the detection of HP12 in Coffs Creek, and the restricted distribution of HP12, found only in a single pool adjacent to the Bellingen township in a contiguous riverine system, provide evidence that at least one such introduction has become established.

While we cannot conclusively eliminate the possibility of natural dispersal events from adjacent drainages, we believe that the most likely scenario is that the Emydura have been introduced to the Bellinger drainage through a series of independent releases; first in the vicinity of Ralph's Crossing in the early 1990s, and the most recent near the township of Bellingen. Emydura species favour complex river systems with a combination of lentic and lotic conditions, including permanent and semi-permanent off-channel billabongs, swamps and wetlands. They do less well in systems with simple river channels and a well-developed closed canopy in the riparian zones and adjacent forest (Georges et al. 2008). It may be that in either case, widespread clearing and altered conditions within the catchment since European settlement have made the river more conducive to the establishment of Emydura species.

The Bellinger Emydura has been used as a flagship 'species' upon which a range of conservation initiatives are based (NSW NPWS 2001). While direct conservation efforts have been arguably misplaced, and perhaps could have been better directed at the phylogenetically distinctive Myuchelys georgesi, which is endemic to this small coastal drainage (Georges 1993), the conservation initiatives linked to the Bellinger River Emydura are of immense value in achieving conservation objectives in the catchment. Downplaying the status of the flagship species presents a particular problem for management. We recommend that the emphasis on the Bellinger Emydura be broadened to also encompass the endemic $M$. georgesi. This shift in focus should be easy to achieve without putting at risk valuable community support for fox control and restoration of riparian vegetation. Subsequently, the emphasis can be further shifted to the local endemic $M$. georgesi, should this be required as more definitive information becomes available, particularly with regard to the risks associated with competition and potential hybridisation between E. macquarii and $M$. georgesi.

There is a salient lesson in the processes leading up to the declaration of the Bellinger Emydura as a listed taxon of conservation concern in state and federal regulations. Our view is not that a mistake was made in drawing upon the precautionary principle at the time of listing the Bellinger Emydura, which has apparently ended up protecting a population of low conservation status. The precautionary principle followed by an adaptive management program (Walters \& Holling 1990) offers an appropriate way out of the paralysis we might otherwise face when a taxon is suspected to be at grave risk and we understand so little about it that we find ourselves unable to identify a truly safe course of action (Doremus 2001). Such an approach, however, should not be a basis for failure to subsequently undertake the fundamental research necessary to reduce uncertainty in the chosen course of action. In this case, the uncertainty arose because of the poor taxonomic knowledge of the Australian Chelidae. Taxonomic research is arguably in decline (Hopkins \& Freckleton 2002), in part because of the discipline's failure to manage the less productive nomenclatural activity eroding perceptions of the value of taxonomic work in the broader scientific community (Godfray 2002, Georges \& Thomson 2010), but also because governments are less willing to support the scientific functions of their museums and to continue to fund staff with taxonomic research capacity. Yet with the looming biodiversity crisis in which turtles appear to be central players (van Dijk et al. 2000, Rhodin et al. 2010), a stable nomenclature for taxonomic concepts that are part of the body of science could not be more important (Spinks et al. 2009, Georges \& Thomson 2010). Without it, resources can be diverted inappropriately (see Smith et al. 1993), regulations that govern wildlife trade circumvented (Kuchling et al. 2007), biodiversity assessments distorted (Agapow et al. 2004, Isaac et al. 2004) and conservation effort wasted. The failure in the case of the 
Bellinger Emydura was that this fundamental taxonomic work was not undertaken soon after the precautionary principle was used to declare it as a vulnerable taxon in the Action Plan for Australian Reptiles (Cogger et al. 1993) and in advance of its listing on state and national conservation schedules.

This case is not isolated. In countries such as Australia, where elements of the flora and fauna are diverse and poorly studied, the precautionary principle commonly comes into play in assessments of conservation status and listing of taxa under the regulatory schedules of state and federal biodiversity conservation acts. If the costs of delay appear higher than the costs of potentially mistaken action, opinion rather than evidence has been an appropriate foundation for action, and weight of opinion was the basis of many of the judgements in the Action Plan for Australian Reptiles. Processes such as these can subsequently lead to the development of action and recovery plans, the implementation of which are fiscally costly and may result in opportunity loss if resources are directed away from more pressing conservation issues. In some cases, development proposals can be halted or substantially modified to meet perceived demands of conservation and environmental sustainability, only to find later that the basis for the environmental concerns was poorly founded. This can serve to erode the commitment of well-minded companies and citizens to appropriately factor environmental concerns in their development plans (Doremus 1997) and serves no one well. The need for objective taxonomic and population data in conservation is critical. A review of the use of anecdotal data for the conservation of 3 high-profile, rare and endangered species led to large errors of omission and commission, which greatly influenced the allocation of limited funds and the efficacy of subsequent conservation efforts (McKelvey et al. 2008).

We advocate the application of the precautionary principle followed by an adaptive approach to species conservation. There needs to be better balance between strategic research and on-ground management action, giving greater emphasis to the former, particularly in the very early stages of any adaptive management regimen. When the issue is regarded as urgent, such as when a new species is discovered or suspected, and perceived to be under threat, the tendency is to do the reverse, viz. to fund action on the ground and neglect the fundamental research of strategic value. The short-term cost savings of this approach may ultimately be greatly exceeded by the longer-term opportunity losses where conservation dollars are limited. Our fundamental conclusion is that taxonomic research should proceed simultaneously with conservation and management, if not before, at least in cases where sound management hinges on taxonomic decisions.
Acknowledgements. We thank the many people who assisted us in the field, but especially J. Faulkner, B. Bailey, C. Eisemberg and M. de la Cueva. We also thank the Bellingen Shire community for their hospitality and assistance with locating sites and providing access to those sites. B. Nesbitt and his team assisted greatly with local knowledge, companionship and assistance in the field. This work was funded by the NSW National Parks and Wildlife Service and Bellinger Landcare, and was approved by the University of Western Sydney animal ethics committee (A6291). The manuscript was prepared as part of the Science Writers Club (Kioloa, December 2009), and we are grateful for the many valuable comments received from participants.

\section{LITERATURE CITED}

Agapow PM, Bininda OR, Crandall KA, Gittleman JL, Mace GM, Marshall JC, Purvis A (2004) The impact of species concept on biodiversity studies. Q Rev Biol 79:161-179

Allanson M, Georges A (1999) Diet of a sibling species pair of freshwater turtles, Elseya purvisi and Elseya georgesi (Testudinata: Chelidae), from eastern Australia. Chelonian Conserv Biol 3:473-476

> Berger L, Speare R, Daszak P, Green DE and others (1998) Chytridiomycosis causes amphibian mortality associated with population declines in the rain forests of Australia and Central America. Proc Natl Acad Sci USA 95: 9031-9036

Blamires SJ, Spencer RJ, King P, Thompson MB (2005) Population parameters and life-table analysis of two co-existing freshwater turtles: are the Bellinger River turtle populations threatened? Wildl Res 32:339-347

Cann J (1998) Australian freshwater turtles. Beaumont Publishing, Singapore

> Clement M, Posada D, Crandall K (2000) TCS: a computer program to estimate gene genealogies. Mol Ecol 9: $1657-1660$

Cogger H (2000) Reptiles and amphibians of Australia. Reed New Holland, Sydney

Cogger H, Cameron E, Sadlier R, Eggler P (1993) The Action Plan for Australian Reptiles. Commonwealth Department of Environment, Heritage and Water (formerly Australian Nature Conservation Agency), Canberra

Commonwealth of Australia (1999) Environment Protection and Biodiversity Conservation (EPBC) Act 1999. Department of the Attorney-General, Canberra

$>$ Daszak P, Berger L, Cunningham AA, Hyatt AD, Green DE, Speare R (1999) Emerging infectious diseases and amphibian population declines. Emerg Infect Dis 5:735-748

de Long DJ (1996) Defining biodiversity. Wildl Soc Bull $24: 738-749$

Doremus H (1997) Listing decisions under the Endangered Species Act: why better science isn't always better policy. Wash Univ Law Q 75:1029

Doremus H (2001) Adaptive management, the Endangered Species Act, and the institutional challenges of 'new age' environmental protection. Washburn Law J 41:50-89

Engstrom TN, Shaffer HB, McCord WP (2004) Multiple data sets, high homoplasy, and the phylogeny of softshell turtles (Testudines: Trionychidae). Syst Biol 53:693-710

Fahrig L (1997) Relative effects of habitat loss and fragmentation on population extinction. J Wildl Manag 61:603-610

> FitzSimmons NN, Limpus CJ, Norman JA, Goldizen AR, Miller JD, Moritz C (1997) Philopatry of male marine turtles inferred from mitochondrial DNA markers. Proc Natl Acad Sci USA 94:8912-8917 
Georges A (1993) Setting conservation priorities for Australian freshwater turtles. In: Lunney D, Ayers D (eds) Herpetology in Australia - a diverse discipline. Royal Society of New South Wales, Sydney, p 49-58

- Georges A, Adams M (1996) Electrophoretic delineation of species boundaries within the short-necked chelid turtles of Australia. Zool J Linn Soc 118:241-260

Georges A, Thomson S (2010) Diversity of Australasian freshwater turtles, with an annotated synonymy and keys to species. Zootaxa 2496:1-37

Georges A, Guarino F, White M (2006) Sex-ratio bias across populations of a freshwater turtle (Testudines: Chelidae) with genotypic sex determination. Wildl Res 33:475-480

Georges A, Alacs E, Pauza M, Kinginapi F, Ona A, Eisemberg C (2008) Freshwater turtles of the Kikori Drainage, Papua New Guinea, with special reference to the pig-nosed turtle, Carettochelys insculpta. Wildl Res 35:700-711

Godfray HCJ (2002) Challenges for taxonomy. Nature 417: $17-19$

Hey J, Waples RS, Arnold ML, Butlin RK, Harrison RG (2003) Understanding and confronting species uncertainty in biology and conservation. Trends Ecol Evol 18:597-603

Hopkins GW, Freckleton RP (2002) Declines in the numbers of amateur and professional taxonomists: implications for conservation. Anim Conserv 5:245-249

Isaac NJB, Mallet J, Mace GM (2004) Taxonomic inflation: its influence on macroecology and conservation. Trends Ecol Evol 19:464-469

Iverson J (1992) A revised checklist with distribution maps of the turtles of the world. Earlham College, Richmond, IN

King P, Heatwole H (1994) Non-pulmonary respiratory surfaces of the chelid turtle Elseya latisternum. Herpetologica 50:262-265

Kuchling G, Rhodin AG, Ibarrondo BR, Trainor CR (2007) A new subspecies of the snakeneck turtle Chelodina mccordi from Timor-Leste (East Timor) (Testudines: Chelidae). Chelonian Conserv Biol 6:213-222

Lauck T, Clark CW, Mangel M, Munro GR (1998) Implementing the precautionary principle in fisheries management through marine reserves. Ecol Appl 8:72-78

Legler J (1960) A simple and inexpensive device for trapping aquatic turtles. Proc Utah Acad Sci 37:63-66

Lips KR, Brem F, Brenes R, Reeve JD and others (2006) Emerging infectious disease and the loss of biodiversity in a Neotropical amphibian community. Proc Natl Acad Sci USA 103:3165-3170

Mace GM (2004) The role of taxonomy in species conservation. Philos Trans R Soc Lond B Biol Sci 359:711-719

McCord W, Cann J, Joseph-Ouni M (2003) A taxonomic assessment of Emydura (Testudines: Chelidae) with descriptions of new subspecies from Queensland, Australia. Reptilia 27:59-63

McGlothlin KL (2004) Loss of biodiversity. Rowman \& Littlefield Publishers, Lanham, MD

McKelvey KS, Aubry KB, Schwartz MK (2008) Using anecdotal occurrence data for rare or elusive species: the illusion of reality and a call for evidentiary standards. Bioscience 58:549-555

Moritz C (1994) Defining evolutionarily significant units for conservation. Trends Ecol Evol 9:373-375

NSW NPWS (New South Wales National Parks and Wildlife Service) (2001) Bellinger River Emydura (Emydura macquarii) recovery plan. NSW NPWS, Sydney

Oliver PM, Lee MSY (2010) The botanical and zoological codes impede biodiversity research by discouraging pub- lication of unnamed new species. Taxon 59:1201-1205

Pauly GB, Piskurek O, Shaffer HB (2007) Phylogeographic concordance in the southeastern United States: the flatwoods salamander, Ambystoma cingulatum, as a test case. Mol Ecol 16:415-429

Raffensperger C, Tickner J, Jackson W (1999) Protecting public health and the environment: implementing the precautionary principle. Island Press, Washington, DC

Rhodin AGJ, van Dijk PP, Iverson JB, Shaffer HB (2010) Turtles of the world, 2010 update: annotated checklist of taxonomy, synonymy, distribution, and conservation status. Chelonian Res Monogr 5:000.85-000.164, doi:10.3854/ crm.5.000.checklist.v3.2010

Rosenberg AA (2003) Managing to the margins: the overexploitation of fisheries. Front Ecol Environ 1:102-106

Smith TB, Bruford MW, Wayne RK (1993) The preservation of process: the missing element of conservation programs. Biodivers Lett 1:164-167

Spencer RJ (2006) The Bellinger River Emydura survey: effects of foxes and interspecific competition. Report to NSW National Parks and Wildlife Service, Dorrigo

Spencer R, Thompson MB (2000) The Bellinger River Emydura survey: the ecology and status of Emydura macquarii and Elseya georgesi in the Bellinger River. Report to NSW National Parks and Wildlife Service, Sydney

Spencer RJ, Georges A, Welsh M (2007) The Bellinger Emydura. Ecology, population status and management. Report to NSW National Parks and Wildlife Service, Sydney

Spinks PQ, Thomson RC, Shaffer HB (2009) A reassessment of Cuora cyclornata Blanck, McCord, and Le, 2006 (Testudines: Geoemydidae) and a plea for taxonomic stability. Zootaxa 2018:58-68

Spinks PQ, Thomson RC, Shaffer HB (2010) Nuclear gene phylogeography reveals the historical legacy of an ancient inland sea on lineages of the western pond turtle, Emys marmorata in California. Mol Ecol 19:542-556

Swofford DL (1996) PAUP*: Phylogenetic analysis using parsimony ( ${ }^{*}$ and other methods), Version 4. 0d59. Sinauer Associates, Sunderland, MA

van Dijk P, Stuart B, Rhodin A (2000) Asian turtle trade. Proceedings of a workshop on conservation and trade of freshwater turtles and tortoises in Asia. Chelonian Res Monogr 2:1-164

Villesen P (2007) FaBox: an online toolbox for FASTA sequences. Mol Ecol Notes 7:965-968

Walters CJ, Holling CS (1990) Large-scale management experiments and learning by doing. Ecology 71: 2060-2068

Walther GR, Post E, Convey P, Menzel A and others (2002) Ecological responses to recent climate change. Nature 416:389-395

Wilson EO, Peter FM (eds) (1988) Biodiversity. National Academy Press, Washington, DC

World Resources Institute (1992) Global biodiversity strategy: guidelines for action to save, study, and use Earth's biotic wealth sustainably and equitably. World Resources Institute, World Conservation Union (IUCN), and United Nations Environment Programme, Washington, DC

Yamaura Y, Amano T, Kusumoto Y, Nagata H, Okabe K (2011) Climate and topography drives macroscale biodiversity through land-use change in a human-dominated world. Oikos 120:427-451

> Zhu D, Degnan S, Moritz C (1998) Evolutionary distinctiveness and status of the endangered Lake Eacham rainbowfish (Melanotaenia eachamensis). Conserv Biol 12:80-93 